\title{
Predictors of Intravesical Recurrence After Radical Nephroureterectomy and Prognosis in Patients with Upper Tract Urothelial Carcinoma
}

This article was published in the following Dove Press journal: Cancer Management and Research

\author{
Yun-Ren Li (D) \\ Kai-Jie Yu iD \\ Ying-Hsu Chang ${ }^{2}$ \\ Po-Hung Lin (iD) \\ I-Hung Shao iD ' \\ Hung-Cheng Kan' \\ Yuan-Cheng Chu' \\ Cheng-Keng Chuang (D) \\ See-Tong Pang' \\ Chung-Yi Liu id ${ }^{2}$ \\ 'Division of Urology, Department of \\ Surgery, Chang Gung Memorial Hospital \\ and Chang Gung University, Taoyuan, \\ Taiwan; ${ }^{2}$ Department of Urology, New \\ Taipei Municipal Tu Cheng Hospital, \\ Chang Gung Memorial Hospital and \\ Chang Gung University, New Taipei City, \\ Taiwan
}

Purpose: We investigate factors that may contribute individually to bladder recurrence and find out the potential candidate to receive postoperative single dose intravesical chemotherapy.

Materials and Methods: A total of 217 patients who were diagnosed with upper tract urothelial carcinoma (UTUC) underwent radical nephroureterectomy (RNU) between 2012 and 2016 in a single hospital. The possible risk factors that may contribute to development of bladder recurrence and overall survival were analysed. In order to find out the relationship between 1st bladder recurrence timing and outcome, we divided the 54 of 56 patients ( 2 patients with prophylactic intravesical chemotherapy excluded) with bladder recurrence after RNU into 2 groups, using the median time of 1 st bladder recurrence and confirmed with the "minimum P-value" approach. The primary endpoint was the development of relapsing high-risk non-muscle invasive bladder cancer (NMIBC). The predictive factors of early recurrence and prognostic factors of survival were also analysed.

Results: Among 217 patients with UTUC under RNU, intravesical recurrence occurred in $56(25.8 \%)$ patients after a median follow-up of 35.2 (1.18-83.34) months. On multivariable analysis, the preoperative ureter manipulation $(p=0.009)$ was a significant predictor for the development of bladder tumours. As for overall survival, renal rein invasion $(p=0.017)$, neutrophil to lymphocyte ratio $(p=0.021)$, and main tumour size $(p=0.015)$ were significant predictors. For 54 patients who developed bladder recurrence, the optimal cut-off point of early recurrence was determined to be 10 months after surgery $(p=0.042)$. Preoperative ureter manipulation $(p=0.005)$ and tumour located both pelvicalyceally and ureterically $(P=0.042)$ were identified as independent factors associated with early recurrence. An end-stage renal disease history and surgical margin positive patient has more late bladder recurrence.

Conclusion: Bladder recurrence was common in UTUC after RNU. Early bladder recurrence was associated with more relapsing high-risk NMIBC and preoperative ureter manipulation was identified as an independent factor associated with early recurrence.

Keywords: intravesical recurrence, prognosis, radical nephroureterectomy, upper tract urothelial carcinoma

\section{Introduction}

Upper tract urothelial carcinoma (UTUC) consists of renal pelvic and ureteral urothelial carcinoma (UC). ${ }^{1}$ Unlike bladder UC, UTUC contributes to $5-10 \%$ of all urothelial tumours, with an estimated annual incidence of 1-2 cases per 100,000 population in the United States. ${ }^{2}$ However, the incidence rate is higher in Taiwan. According to the Taiwan Cancer Registry Annual Report in 2016, the age-standardized incidence rate of
Correspondence: Chung-Yi Liu

Municipal Tu Cheng Hospital, Chang Gung

Memorial Hospital and Chang Gung

University, No. 6, Sec.2, JinCheng Road,

Tucheng District, New Taipei City 236,

Taiwan

Tel +886-2-22630588 ext. 6230

Fax +886-2-22732688

Email littleteco@gmail.com
Cancer Management and Research 2020:12 7439-7450

7439

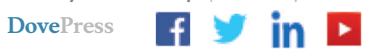

the: $1 / 4$ in 
UTUC per 100,000 population was 3.61 and 4.21 among men and women, respectively, which comprises up to $30 \%$ of all UCs in Taiwan. ${ }^{3}$

The standard surgical treatment of UTUC is radical nephroureterectomy (RNU) with bladder cuff excision. Despite treatment with standard surgery, tumour recurrence is common, especially intravesical recurrence (IVR). A meta-analysis showed that the incidence of IVR was $29 \%$, with a median time of 22.2 months (range 6.7-56.5 months). ${ }^{4}$ Previous studies have proposed the predictor of IVR, but the definite pathophysiology of bladder recurrence remains unclear. Two theories have been proposed to explain the possibility of frequent urothelial cancer recurrence: implantation of a tumour cell of monoclonal origin after intraluminal seeding ${ }^{5}$ or field-cancerization theory ${ }^{6}$ or both. Studies on prophylactic instillation of intravesical chemotherapy (IVCT) after RNU have been reported with the number needed to treat as 9 to reduce the risk of IVR. ${ }^{7}$ However, considering the potential extravasation of chemotherapy, immediate instillation was not routinely performed for every high-risk patient. Therefore, accurate prediction of IVR is necessary to identify the best candidates.

The aim of this study was to investigate factors that may contribute individually to recurrence of bladder carcinoma and identify potential candidates to undergo prophylactic intravesical chemotherapy.

\section{Materials and Methods}

A total of 373 patients were diagnosed with primary UTUC between January 2012 and December 2016 at Linkou Chang Gung Memorial Hospital. The study protocol was approved by the Institutional Review Board at the Chang Gung Memorial Hospital (Taoyuan, Taiwan) (IRB: 201601299B0C602). The patients' consent to review their medical records was waived by the IRB of Chang-Gung Memorial Hospital due to retrospective study. The patient data confidentiality fulfilled the Declaration of Helsinki. The following were excluded from the study: 12 patients who were lost to follow-up within 3 months, 55 who received systemic chemotherapy, 52 who did not undergo surgical intervention, 6 who underwent concomitant radical cystectomy, 13 who did not receive standard radical nephroureterectomy, 7 who had double active cancer, and 10 who had previous/concurrent bladder UC. One patient underwent complete resection of the tumour during diagnostic ureteroscopy, and the final pathology of nephroureterectomy showed no residual malignant tumour. The clinical data of the remaining 217 patients were retrospectively reviewed.

To determine the relation between bladder recurrence free survival time and prognosis, 54 patients with current IVR were analysed ( 2 patients were excluded owing to prophylactic intravesical chemotherapy). The timing of IVR was within postoperative 24 months, and the median time was 10 months. Therefore, we grouped the patients with bladder recurrence into early and late recurrence, using the median time of 1 st bladder recurrence and confirmed with the "minimum P-value" approach. The "minimum P-value" approach, which was performed using the $\log$ rank test for the time to relapsing high-risk NMIBC after radical nephroureterectomy, was used to determine the best cut-off with which to divide up patients based on the time to relapsing high-risk NMIBC after radical nephroureterectomy. The minimum P-value approach has been proposed as a means of reducing the risk of missing a significant association in previous studies. ${ }^{16,17}$ Further analysis was performed between the two groups.

UTUC was diagnosed by intravenous urography, computed tomographic urography, magnetic resonance imaging, or diagnostic ureteroscopy. Preoperative cystoscopy was performed in all patients to rule out concurrent bladder tumour. Regional lymph node dissection was not routinely performed in our cases.

According to the Clinical Practice Guidelines in Oncology (NCCN Guidelines), the standard management of upper tract urothelial carcinoma is standard RNU, included nephroureterectomy and ipsilateral bladder cuff excision. Several techniques has been described for bladder cuff excision; in our hospital, an extravesical approach was selected. When performing the extravesical approach of bladder cuff excision, the distal ureter is freed towards the bladder to the point of intramural ureter. The cuff of bladder is removed en bloc with the ureter by applying a clamp to the bladder wall and excising the full intramural portion of the ureter. We defined the bladder cuff excision by reviewing the operation record. All of the surgical records showed bladder cuff removed.

In our institute, cystoscopy was performed every 3 months after RNU for the first 2 years. The interval of cystoscopy was extended to every 6 months in the $3^{\text {rd }}$ and $4^{\text {th }}$ years after surgery, and then annually thereafter. Compared to the European Association of Urology (EAU) and National Comprehensive Cancer Network (NCCN) follow-up guidelines, we follow a more intensive cystoscopic examination. Bladder recurrence was defined as tumours identified on 
Table I Clinicopathologic Characteristics of Patients with UTUC Treated by RNU

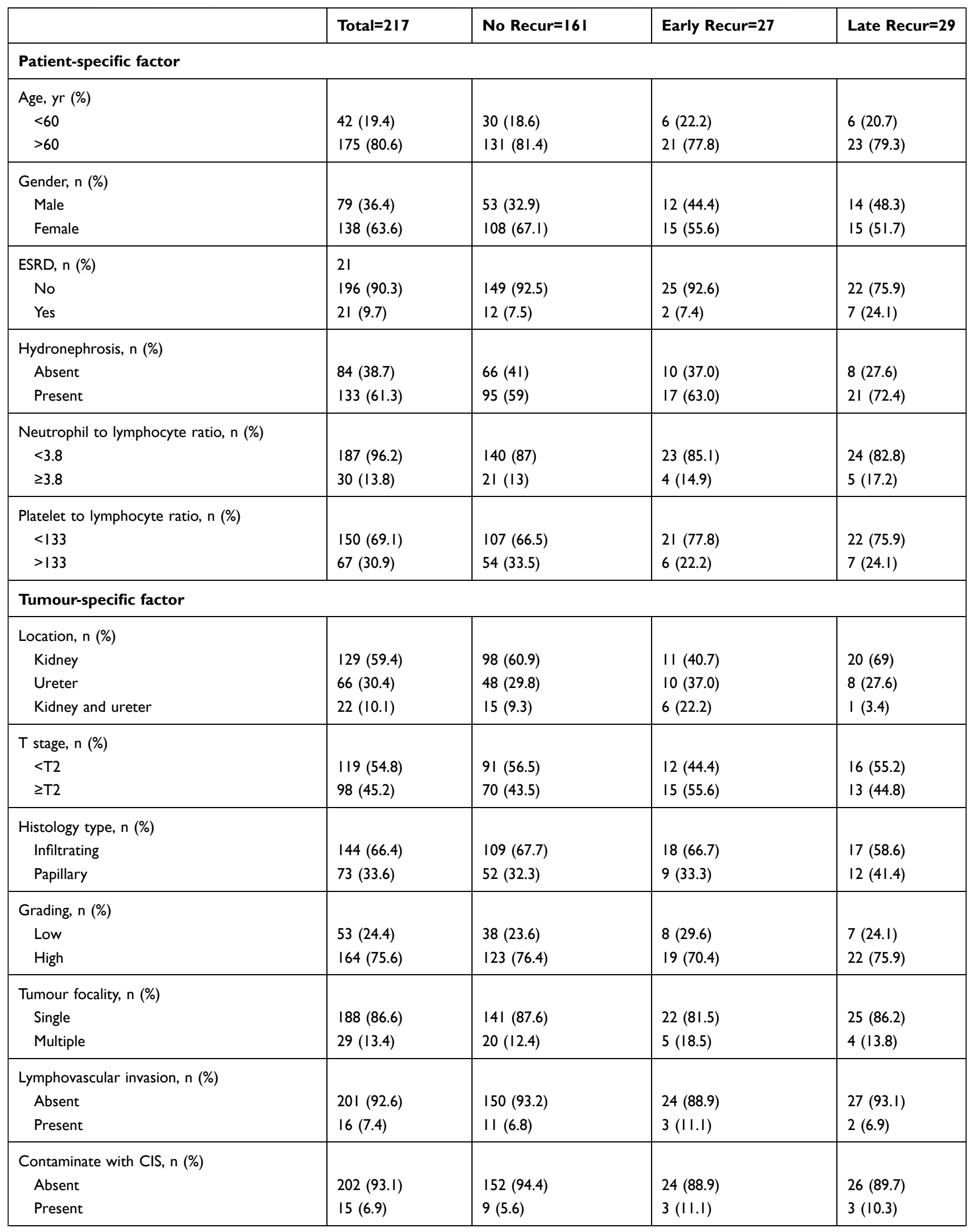

(Continued) 
Table I (Continued).

\begin{tabular}{|c|c|c|c|c|}
\hline & Total $=217$ & No Recur $=161$ & Early Recur=27 & Late Recur $=\mathbf{2 9}$ \\
\hline \multicolumn{5}{|l|}{ Renal vein invasion, $\mathrm{n}(\%)$} \\
\hline Absent & $214(98.6)$ & $159(98.8)$ & $27(100)$ & $28(96.6)$ \\
\hline Present & $3(1.4)$ & $2(1.2)$ & $0(0)$ & I (3.4) \\
\hline \multicolumn{5}{|l|}{ Main tumour } \\
\hline$<6.7 \mathrm{~mm}$ & $206(94.9)$ & $150(93.2)$ & $27(100)$ & $29(100)$ \\
\hline$\geq 6.7 \mathrm{~mm}$ & I I(5.I) & II (6.8) & $0(0)$ & $0(0)$ \\
\hline \multicolumn{5}{|l|}{ Treatment-specific factor } \\
\hline \multicolumn{5}{|c|}{ Preop ureter manipulation, n (\%) } \\
\hline Absent & $81(37.3)$ & $69(42.9)$ & $3(11.1)$ & $9(3 I)$ \\
\hline Present & $136(62.7)$ & $92(57.1)$ & $24(88.9)$ & $20(69)$ \\
\hline \multicolumn{5}{|l|}{ Surgical approach, n (\%) } \\
\hline Open method & $96(44.2)$ & $75(46.6)$ & $9(33.3)$ & $12(4 \mid .4)$ \\
\hline Laparoscopic method & $106(48.8)$ & $76(47.2)$ & $16(59.3)$ & $14(48.3)$ \\
\hline Robotic assisted method & $15(6.9)$ & $10(6.2)$ & $2(7.4)$ & $3(10.3)$ \\
\hline \multicolumn{5}{|l|}{ Complication, n (\%) } \\
\hline Absent & $215(99.1)$ & $159(98.8)$ & $27(100)$ & $29(100)$ \\
\hline Present & $2(0.9)$ & $2(1.2)$ & $0(0)$ & $0(0)$ \\
\hline \multicolumn{5}{|l|}{ Surgical margin, $n(\%)$} \\
\hline Free & $215(99.1)$ & $161(100)$ & $27(100)$ & $27(93.1)$ \\
\hline Positive & $2(0.9)$ & $0(0)$ & $0(0)$ & $2(6.9)$ \\
\hline \multicolumn{5}{|l|}{ Bladder recurrence } \\
\hline Absent & 161 (74.2) & $161(100)$ & $0(0)$ & $0(0)$ \\
\hline Present & $56(25.8)$ & $0(0)$ & $27(100)$ & 29 \\
\hline \multicolumn{5}{|l|}{ Prophylactic IVC, n (\%) } \\
\hline No use & $206(94.9)$ & $152(94.4)$ & $0(0)$ & $27(93.1)$ \\
\hline Epirubicin & $7(3.2)$ & $5(3.1)$ & $0(0)$ & $2(6.9)$ \\
\hline MMC & $4(1.8)$ & $4(2.5)$ & $0(0)$ & $0(0)$ \\
\hline
\end{tabular}

cystoscopy and confirmed by pathology. The relapsing highrisk non-muscle-invasive bladder tumour was defined as the $2^{\text {nd }}$ recurrence of bladder tumour with high risk (T1, highgrade, multiple tumours) when it developed after complete resection of the $1^{\text {st }}$ IVR and completion of intravesical chemotherapy (epirubicin or mitomycin C). The cause of death was collected using death certificates. Follow-ups were censored until their last visit or death.

Categorical variables were compared using the chisquare test. Survival analyses were performed using the Kaplan-Meier method and were compared using the log rank test. Variables in which the $p$ value for the univariate analysis was $<0.05$ were subjected to either multivariate logistic regression or the Cox regression model. All reported $p$ values were single sided with statistical significance considered at $p<0.05$. All statistical analyses were performed using IBM SPSS Statistics 22 software.

\section{Results}

Table 1 reveals the clinicopathologic characteristics of 217 patients with primary UTUC treated using standard radical nephroureterectomy in our institution between January 2012 and December 2016. The median age was 70 (34-90) years, and $138(63.6 \%)$ patients were female. The median followup period was 42.0 (1.18-83.34) months. Twenty-one (9.7\%) patients had a history of end-stage renal disease and were under renal replacement therapy. Open RNU was performed in $96(44.2 \%)$ patients, laparoscopic method in $106(48.8 \%)$ patients, and robotic-assisted method in 15 (6.9\%) patients. 
The tumours were pelvicalyceal in $129(59.4 \%)$ patients, ureteric in 66 (30.4\%), and both pelvicalyceal and ureteric in $22(10.1 \%)$ patients. IVCT was not routinely arranged after surgery, there were only 11 patients who received the installation (epirubicin 7 cases and mitomycin 4 cases).

The tumour stage was <T2 in $119(54.8 \%)$ patients and $\geq \mathrm{T} 2$ in $98(45.2 \%)$ patients. Histology with infiltrating type $(66.4 \%)$ and high-grade tumours $(75.6 \%)$ were predominant. As for additional pathological finding, lymphovascular invasion (LVI) was seen in $7.4 \%$ of patients, concomitant carcinoma in situ (CIS) in 6.9\%, renal vein invasion in $1.4 \%$, and surgical margin positive in $2.8 \%$ of patients.

IVR after RNU was noted in $56(25.8 \%)$ patients after a median follow-up of 35.2 (1.18-83.34) months. The recurrent bladder tumours were managed with endoscopic resection and intravesical chemoimmunotherapy following the standard protocol. The recurrent bladder tumours showed the following characteristics: $71.4 \%, 26.8 \%$, and $1.8 \%$ of tumours were in $\mathrm{Ta}, \mathrm{T} 1$, and $\mathrm{T} 2$ stages,

\section{A Preoperative ureter manipulation}

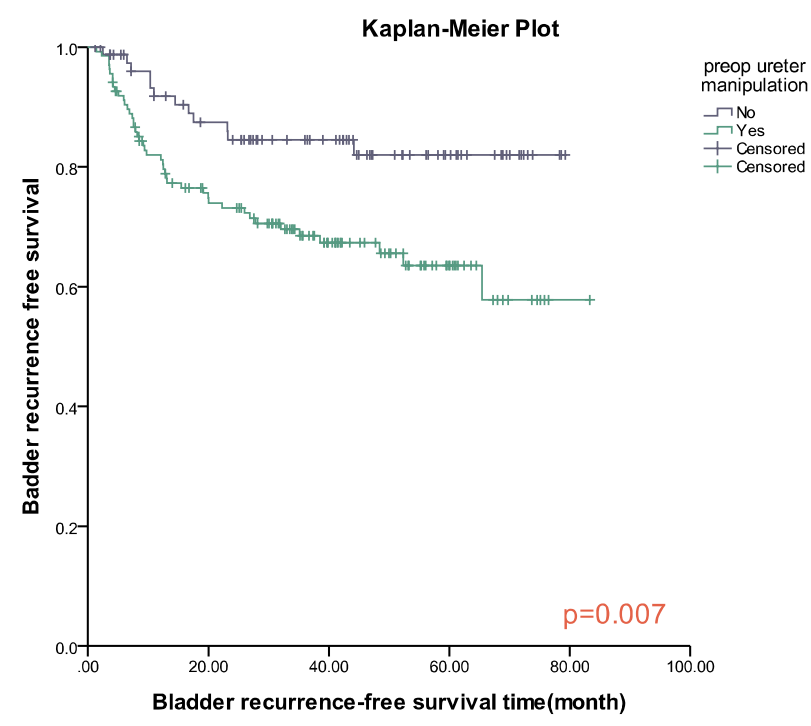

\section{Surgical margin}

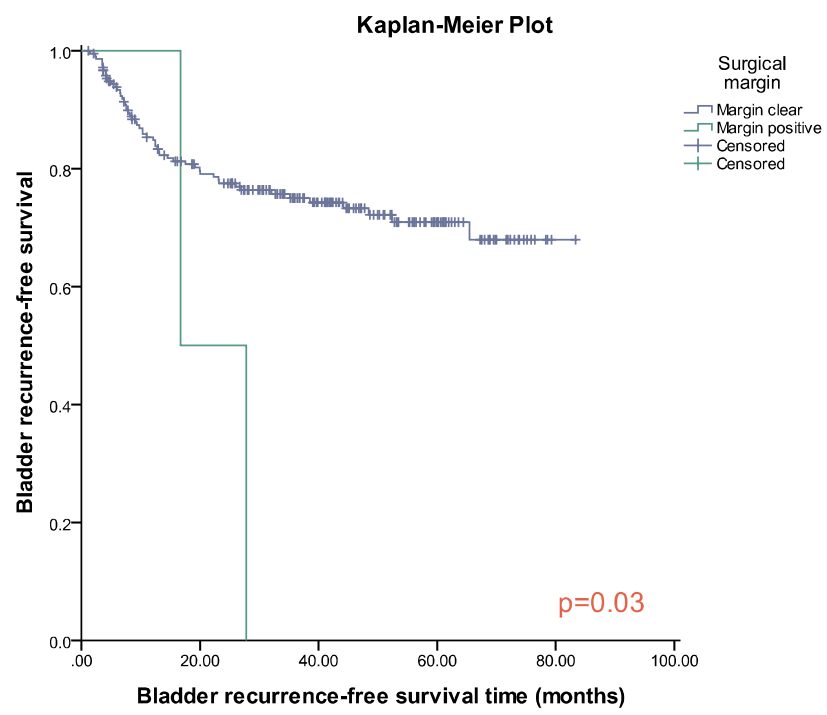

\section{B Contamination with CIS}

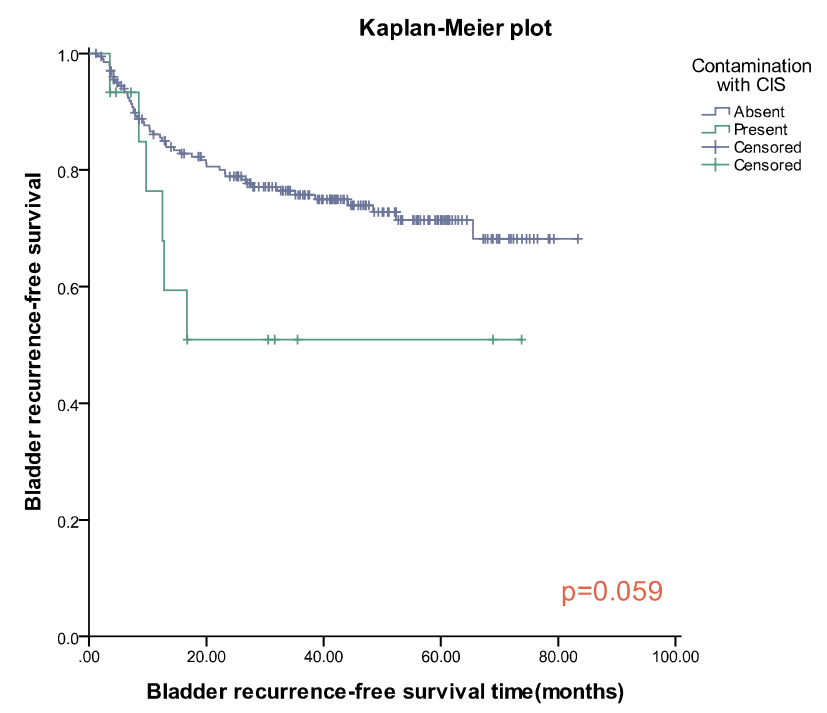

D Main tumor size

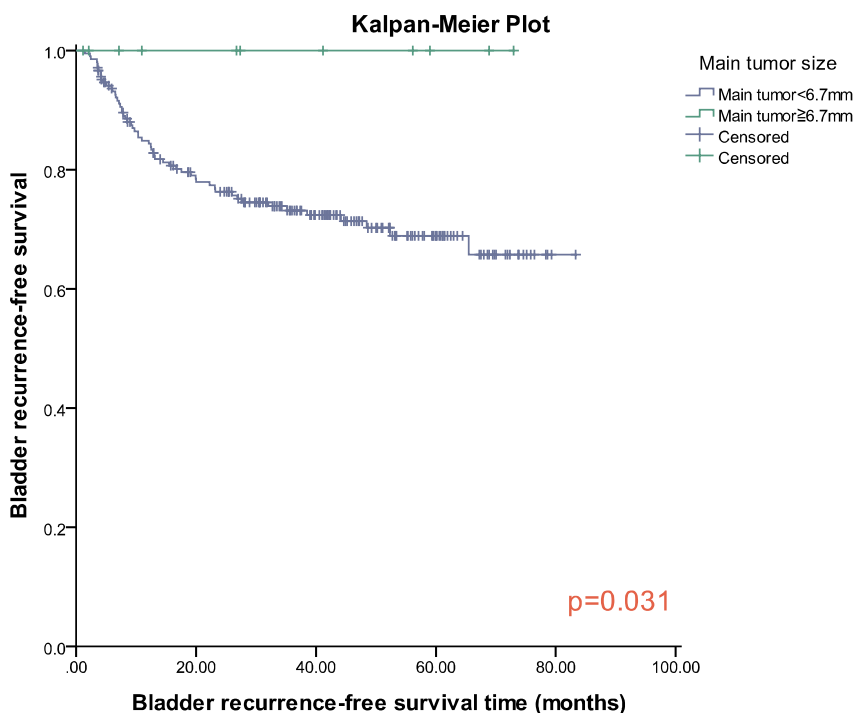

Figure I Kaplan-Meier estimates of bladder recurrence free survival: (A) preoperative ureter manipulation; (B) contamination with CIS; (C) surgical margin; (D) main tumour size. 
A Neutrophil-Lymphocyte ratio

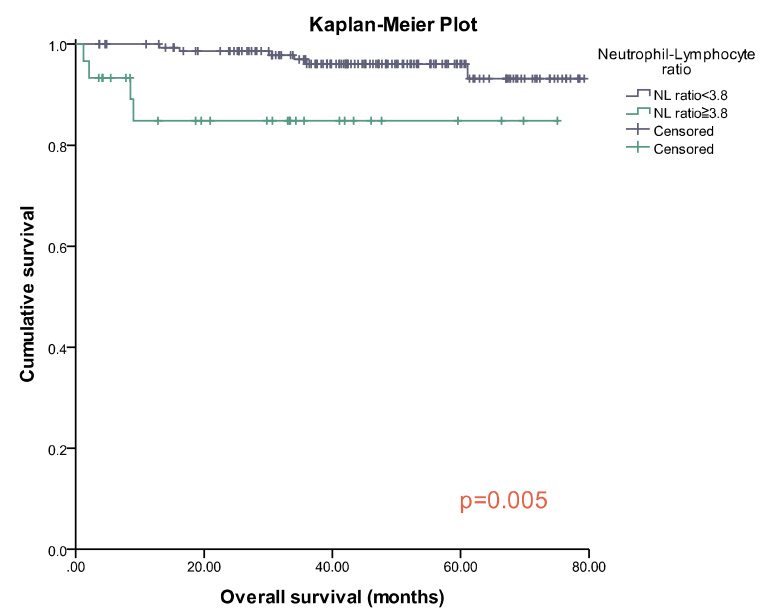

C Tumor histology type

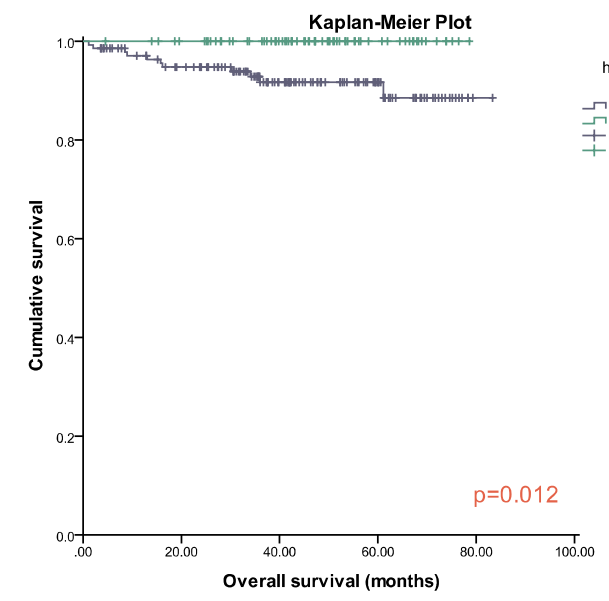

E Renal vein invasion

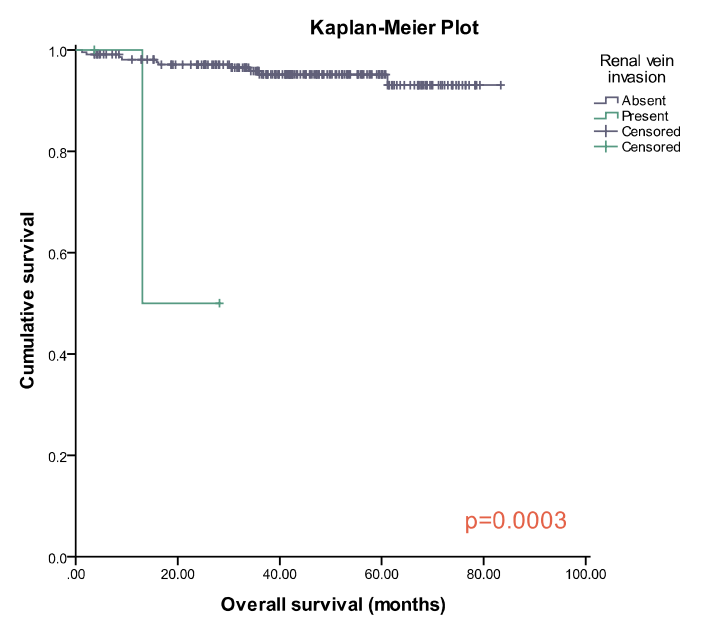

\section{B T stage}

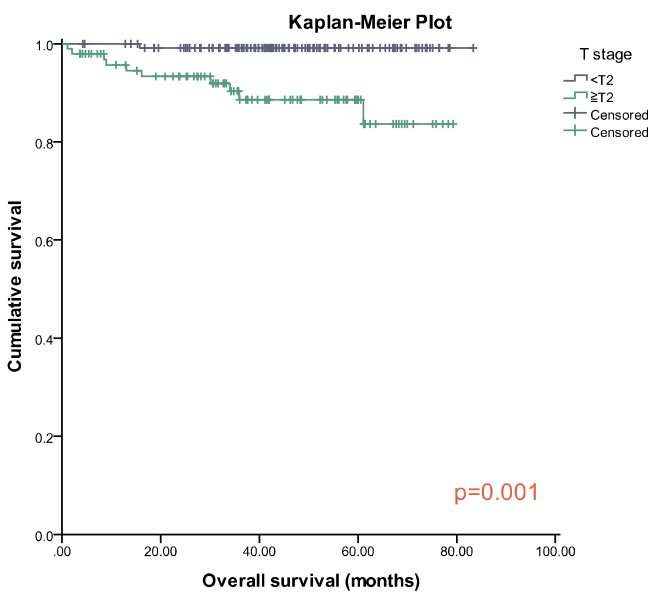

D Tumor grading

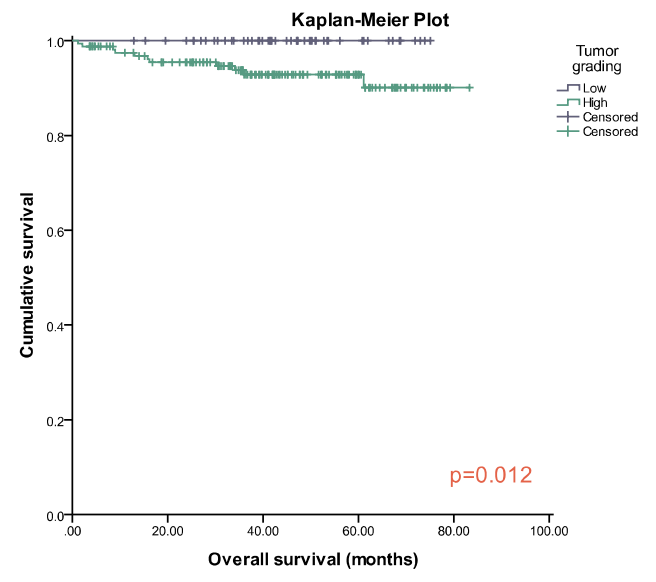

F Main tumor size

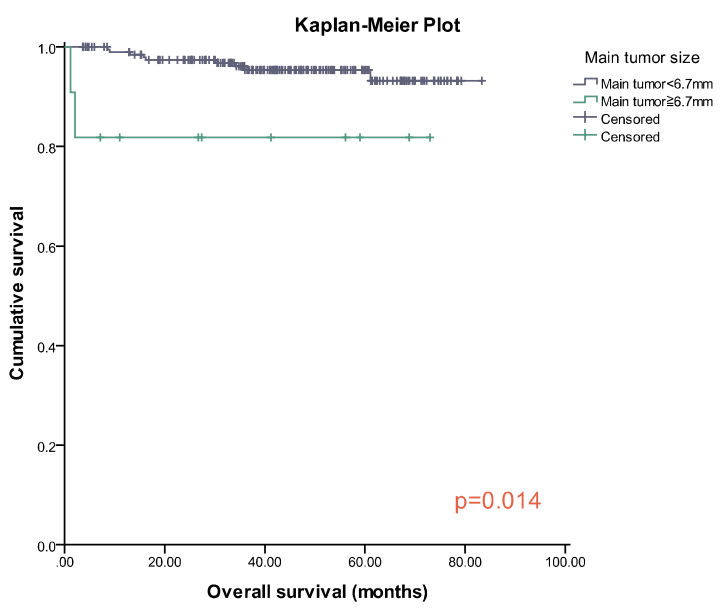

Figure 2 Kaplan-Meier estimates of overall survival: (A) neutrophil to lymphocyte ratio; (B) T stage; (C) tumour histology type; (D) tumour grading; (E) renal vein invasion; (F) main tumour size. 
respectively. Refractory bladder tumours were noted in 16 patients $(28.6 \%)$. One patient underwent radical cystectomy after refractory muscle invasive bladder tumour and contralateral UTUC developed. Two patients had partial cystectomy after multiple endoscopic resection of $\mathrm{T} 1$ tumour and intravesical chemotherapy failed.

We analysed the possible risk factors of developing bladder tumours after RNUs. Univariate analysis showed that preoperative ureter manipulation, contamination with carcinoma in situ (CIS), positive surgical margin, and main tumour size $>6.7 \mathrm{~mm}$ had more bladder recurrences (Figure 1). Preoperative ureter manipulation (HR: 2.42, $p=0.009$ ) was an independent predictor for development of bladder tumours. As for overall survival, univariate analysis showed that the neutrophil to lymphocyte ratio (NLR), T stage, tumour histology type, tumour grading, presence of renal vein invasion, and tumour size were significant factors for overall survival (Figure 2). Renal vein invasion (HR: 17.7, $p=0.017$ ), pre-operation NLR (HR: 4.793, $p=0.021$ ), and main tumour size (HR: 7.912, $p=0.015$ ) were independent predictors for overall survival.

Since there were scarce cases who received prophylactic IVCT after RNU (11 of 217 patients) and only
2 of them developed bladder recurrence, we excluded them and performed further analysis. We divided the rest of 54 patients with bladder recurrence after RNU into early recurrence ( $<10$ months) and late recurrence ( $>10$ months) groups based on the timing of bladder recurrence. The overall survival showed no difference between groups. Figure 3 shows that the early recurrence group ( $<10$ months) is associated with shorter time to develop relapsing high-risk non-muscle invasive bladder cancer $(p=0.042)$, which may cause further cystectomy or concurrent chemoradiation therapy. Relapsing high-risk non-muscle invasive bladder cancer was observed in 7 patients. In addition, we examined the risk factors for early recurrence within 10 months after RNU for UTUC using 206 patients who underwent RNU for UTUC and without prophylactic IVCT. Table 2 shows the results of the $\chi^{2}$ test and the logistic regression model used to analyse the clinicopathological factors related to early recurrence. Preoperative ureter manipulation (HR: 6.27, $p=0.005$ ) and tumour located both pelvicalyceally and ureterically (HR: 4.681, $p=0.042$ ) were identified as an independent factor associated with early recurrence.

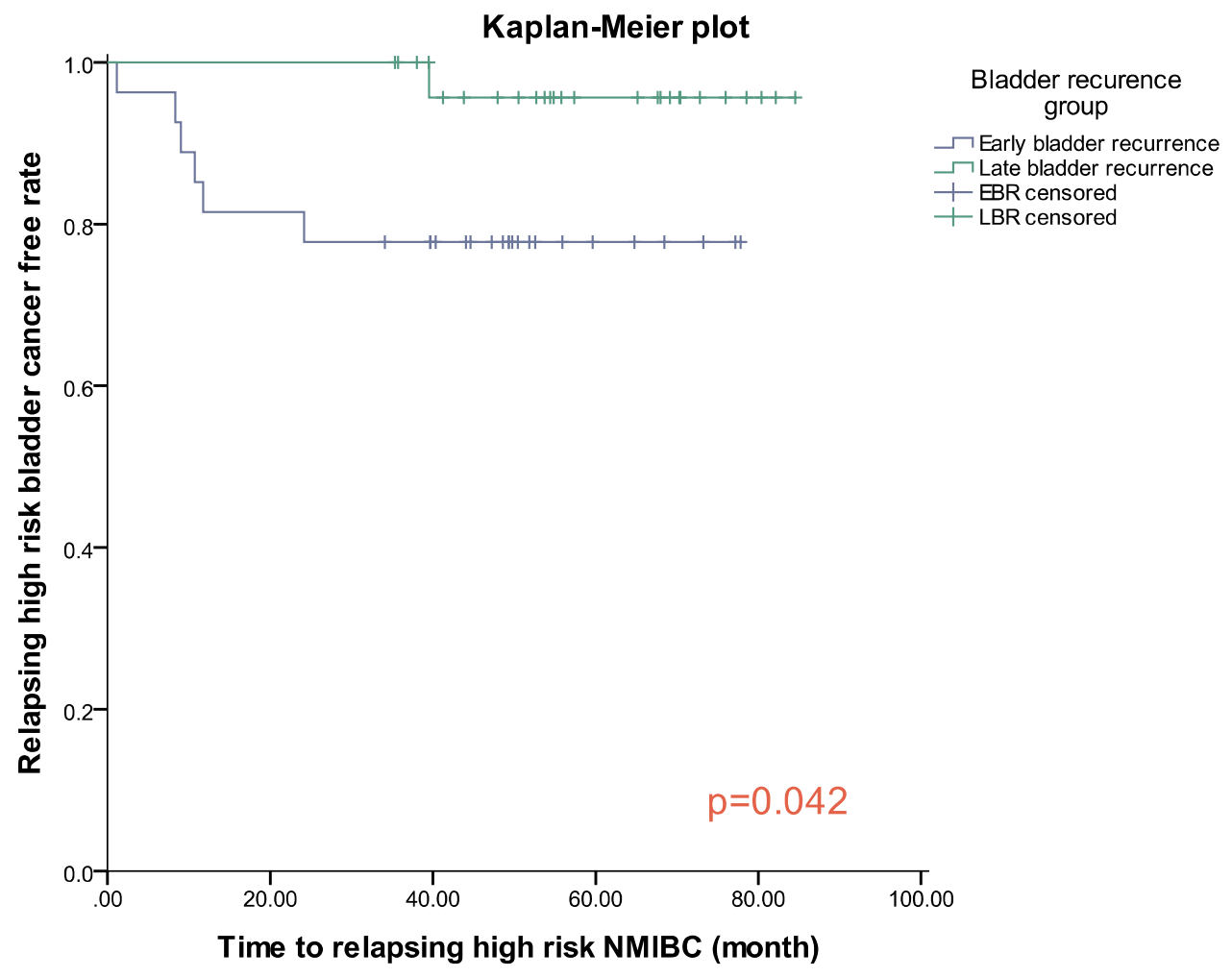

Figure 3 Relationship between early recurrence group ( $<10$ months) and risk of developing relapsing high-risk non-muscle invasive bladder cancer: early recurrence group $(<10$ months) is associated with shorter time to develop relapsing high-risk non-muscle invasive bladder cancer $(p=0.042)$. 
Table 2 Results of the Univariate and Multivariate Analyses of the Clinicopathologic Factors of Early Recurrence Group (Without Prophylactic Intravesical Chemotherapy)

\begin{tabular}{|c|c|c|c|c|c|}
\hline & \multirow[t]{2}{*}{ Early Recur=27 } & \multirow[t]{2}{*}{ Other $=179$} & \multirow[t]{2}{*}{ Univariate Analysis, $p$} & \multicolumn{2}{|l|}{ Multivariate Analysis } \\
\hline & & & & HR $(95 \% \mathrm{Cl})$ & $p$ \\
\hline \multicolumn{6}{|l|}{ Patient-specific factor } \\
\hline Age, yr (\%) & & & 0.693 & & \\
\hline$<60$ & $6(22.2)$ & 34 & & & \\
\hline$>60$ & $21(77.8)$ & 145 & & & \\
\hline Gender, n (\%) & & & 0.383 & & \\
\hline Male & $12(44.4)$ & 64 & & & \\
\hline Female & $15(55.6)$ & 115 & & & \\
\hline ESRD, n (\%) & & & 0.608 & & \\
\hline No & $25(92.6)$ & 160 & & & \\
\hline Yes & $2(7.4)$ & 19 & & & \\
\hline Hydronephrosis, n (\%) & & & 0.847 & & \\
\hline Absent & $10(37.0)$ & 69 & & & \\
\hline Present & $17(63.0)$ & 108 & & & \\
\hline Neutrophil to lymphocyte ratio, n (\%) & & & 0.866 & & \\
\hline$<3.8$ & $23(85.1)$ & 155 & & & \\
\hline$\geq 3.8$ & $4(14.9)$ & 24 & & & \\
\hline Platelet to lymphocyte ratio, n (\%) & & & 0.232 & & \\
\hline$<133$ & $21(77.8)$ & 122 & & & \\
\hline$>133$ & $6(22.2)$ & 57 & & & \\
\hline \multicolumn{6}{|l|}{ Tumour-specific factor } \\
\hline Location, n (\%) & & & 0.031 & & 0.042 \\
\hline Kidney & II (40.7) & 113 & & I & \\
\hline Ureter & $10(37.0)$ & 51 & & $1.346(0.523-3.466)$ & \\
\hline Kidney and ureter & $6(22.2)$ & 15 & & $4.68 I(1.40 I-15.643)$ & \\
\hline T stage, n (\%) & & & 0.267 & & \\
\hline$<\mathrm{T} 2$ & $12(44.4)$ & 100 & & & \\
\hline$\geq \mathrm{T} 2$ & I5 (55.6) & 79 & & & \\
\hline Histology type, n (\%) & & & 0.939 & & \\
\hline Infiltrating & $18(66.7)$ & 118 & & & \\
\hline Papillary & $9(33.3)$ & 61 & & & \\
\hline Grading, n (\%) & & & 0.54 & & \\
\hline Low & $8(29.6)$ & 43 & & & \\
\hline High & $19(70.4)$ & 135 & & & \\
\hline Tumour focality, n (\%) & & & 0.371 & & \\
\hline Single & $22(81.5)$ & 157 & & & \\
\hline Multiple & $5(18.5)$ & 22 & & & \\
\hline Lymphovascular invasion, n (\%) & & & 0.486 & & \\
\hline Absent & $24(88.9)$ & 166 & & & \\
\hline Present & $3(11.1)$ & 13 & & & \\
\hline
\end{tabular}

(Continued) 
Table 2 (Continued).

\begin{tabular}{|c|c|c|c|c|c|}
\hline & \multirow[t]{2}{*}{ Early Recur $=27$} & \multirow[t]{2}{*}{ Other $=179$} & \multirow[t]{2}{*}{ Univariate Analysis, $p$} & \multicolumn{2}{|c|}{ Multivariate Analysis } \\
\hline & & & & HR (95\% CI) & $p$ \\
\hline Contaminate with CIS, n (\%) & & & $0.4 I I$ & & \\
\hline Absent & $24(88.9)$ & 167 & & & \\
\hline Present & $3(11.1)$ & 12 & & & \\
\hline Renal vein invasion, $\mathrm{n}(\%)$ & & & 0.498 & & \\
\hline Absent & $27(100)$ & 176 & & & \\
\hline Present & $0(0)$ & 3 & & & \\
\hline Main tumour, n (\%) & & & 0.208 & & \\
\hline$<6.7 \mathrm{~mm}$ & $27(100)$ & 169 & & & \\
\hline$\geq 6.7 \mathrm{~mm}$ & $0(0)$ & 10 & & & \\
\hline \multicolumn{6}{|l|}{ Treatment-specific factor } \\
\hline Preop ureter manipulation, $\mathrm{n}(\%)$ & & & 0.002 & & 0.005 \\
\hline Absent & $3(11.1)$ & 75 & & I & \\
\hline Present & $24(88.9)$ & 104 & & $6.27(1.722-22.826)$ & \\
\hline Surgical approach, n (\%) & & & 0.523 & & \\
\hline Open method & $9(33.3)$ & 80 & & & \\
\hline Laparoscopic method & $16(59.3)$ & 86 & & & \\
\hline Robotic assisted method & $2(7.4)$ & 13 & & & \\
\hline Complication, n (\%) & & & 0.697 & & \\
\hline Absent & $27(100)$ & 178 & & & \\
\hline Present & $0(0)$ & 1 & & & \\
\hline Surgical margin, n (\%) & & & $0.58 I$ & & \\
\hline Free & $27(100)$ & 177 & & & \\
\hline Positive & $0(0)$ & 2 & & & \\
\hline
\end{tabular}

Late recurrence was observed in 27 patients. The factors related to late recurrence were investigated in 145 patients who were confirmed to be recurrence free 10 months after RNU. Table 3 shows the results of the univariate and multivariate analyses of the clinicopathologic factors contributing to the late recurrence. An endstage renal disease (ESRD) history and surgical margin positive have more late bladder recurrence; however, the results were not significant.

\section{Discussion}

We demonstrated a relatively large number of patients with UTUC who received RNU at a single institute in Taiwan. A previous study showed that the peak of IVR was detected in the early period $(<2.5$ years) after surgery, and the IVR hazard decreased afterwards. ${ }^{8}$ In our study, $25.8 \%$ patients presented with bladder recurrence with a median time to IVR 10 months after a median follow- up of 35.2 (1.18-83.34) months, which concurs with the results of a previous meta-analysis which showed $29 \%$ IVR in a median time to IVR of $22.2(6.7-56.5)$ months. $^{4}$

Several studies have been published to identify patients at a higher risk of IVR after RNU. However, limited studies have discussed about the impact of the timing of intravesical bladder recurrence in UTUC. In our study, early recurrence (within 10 months) was significantly associated with relapsing high-risk non-muscle invasive bladder cancer ( $p=0.042$ ), which may contribute further to muscle invasive bladder cancer and poor oncological outcomes. Previous studies showed that IVR did not have an impact on recurrent free survival (RFS) and cancer-specific survival (CSS). ${ }^{9,10}$ Kim et $\mathrm{al}^{9}$ demonstrated that patients with muscle invasive bladder cancer (MIBC) had significantly worse CSS than those without MIBC. Therefore, further study should emphasize risk analysis of patients with bladder recurrence with MIBC and high-risk non-MIBC (NMIBC). 
Table 3 Results of the Univariate and Multivariate Analyses of the Clinicopathologic Factors of Late Recurrence Group (Without Prophylactic Intravesical Chemotherapy)

\begin{tabular}{|c|c|c|c|c|c|}
\hline & \multirow[t]{2}{*}{ Late Group=27 } & \multirow[t]{2}{*}{ Other $=137$} & \multirow[t]{2}{*}{ Univariate Analysis, $p$} & \multicolumn{2}{|c|}{ Multivariate Analysis } \\
\hline & & & & HR $(95 \% \mathrm{Cl})$ & $p$ \\
\hline \multicolumn{6}{|l|}{ Patient-specific factor } \\
\hline Age, yr (\%) & & & 0.697 & & \\
\hline$<60$ & 6 & 26 & & & \\
\hline$>60$ & 21 & III & & & \\
\hline Gender, n (\%) & & & 0.072 & & \\
\hline Male & 14 & 46 & & & \\
\hline Female & 13 & 91 & & & \\
\hline ESRD, n (\%) & & & 0.011 & & 0.101 \\
\hline No & 20 & 125 & & & \\
\hline Yes & 7 & 12 & & $2.604(0.829-8.184)$ & \\
\hline Hydronephrosis, n (\%) & & & 0.28 & & \\
\hline Absent & 8 & 55 & & & \\
\hline Present & 19 & 80 & & & \\
\hline Neutrophil to lymphocyte ratio, n (\%) & & & 0.278 & & \\
\hline$<3.8$ & 22 & 126 & & & \\
\hline$\geq 3.8$ & 4 & 11 & & & \\
\hline Platelet to lymphocyte ratio, n (\%) & & & 0.272 & & \\
\hline$<133$ & 21 & 95 & & & \\
\hline$>133$ & 6 & 42 & & & \\
\hline \multicolumn{6}{|l|}{ Tumour-specific factor } \\
\hline Location, n (\%) & & & 0.249 & & \\
\hline Kidney & 20 & 79 & & & \\
\hline Ureter & 6 & 44 & & & \\
\hline Kidney and ureter & I & 14 & & & \\
\hline \multicolumn{6}{|l|}{ T stage, $n(\%)$} \\
\hline$<\mathrm{T} 2$ & & & & & \\
\hline$\geq \mathrm{T} 2$ & & & & & \\
\hline Histology type, n (\%) & & & 0.354 & & \\
\hline Infiltrating & 15 & 89 & & & \\
\hline Papillary & 12 & 48 & & & \\
\hline Grading, n (\%) & & & 0.953 & & \\
\hline Low & 7 & 36 & & & \\
\hline High & 20 & 101 & & & \\
\hline Tumour focality, n (\%) & & & 0.815 & & \\
\hline Single & 23 & 119 & & & \\
\hline Multiple & 4 & 18 & & & \\
\hline Lymphovascular invasion, n (\%) & & & 0.504 & & \\
\hline Absent & 25 & 131 & & & \\
\hline Present & 2 & 6 & & & \\
\hline
\end{tabular}

(Continued) 
Table 3 (Continued).

\begin{tabular}{|c|c|c|c|c|c|}
\hline & \multirow[t]{2}{*}{ Late Group=27 } & \multirow[t]{2}{*}{ Other $=137$} & \multirow[t]{2}{*}{ Univariate Analysis, $p$} & \multicolumn{2}{|c|}{ Multivariate Analysis } \\
\hline & & & & HR (95\% Cl) & $p$ \\
\hline Contaminate with CIS, n (\%) & & & 0.16 & & \\
\hline Absent & 24 & $|3|$ & & & \\
\hline Present & 3 & 6 & & & \\
\hline Renal vein invasion, $\mathrm{n}(\%)$ & & & 0.198 & & \\
\hline Absent & 26 & 136 & & & \\
\hline Present & 1 & I & & & \\
\hline Main tumour & & & 0.23 & & \\
\hline$<6.7 \mathrm{~mm}$ & 27 & 130 & & & \\
\hline$\geq 6.7 \mathrm{~mm}$ & 0 & 7 & & & \\
\hline \multicolumn{6}{|l|}{ Treatment-specific factor } \\
\hline Preop ureter manipulation, n (\%) & & & 0.423 & & \\
\hline Absent & 9 & 57 & & & \\
\hline Present & 18 & 80 & & & \\
\hline Surgical approach, n (\%) & & & 0.771 & & \\
\hline Open method & 11 & 62 & & & \\
\hline Laparoscopic method & 13 & 65 & & & \\
\hline Robotic assisted method & 3 & 10 & & & \\
\hline Complication, n (\%) & & & 0.656 & & \\
\hline Absent & 27 & 136 & & & \\
\hline Present & 0 & 1 & & & \\
\hline Surgical margin, n (\%) & & & 0.001 & & 0.999 \\
\hline Free & 25 & 137 & & & \\
\hline Positive & 2 & 0 & & & \\
\hline
\end{tabular}

The NLR, an indicator of the presence of systemic inflammation, has been identified as a biomarker for predicting the poor prognosis and recurrence in cancer patients. $^{11,12}$ A previous study showed that high NLR significantly increased the risk for CSS, RFS, and overall survival (OS); ${ }^{13}$ these results were consistent with our results.

In our study, the male to female ratio of UTUC was $1: 1.75$, showing a female-predominant result but did not show significant difference during analysis. Similarly, the Taiwan Cancer Registry Annual Report in 2016 also revealed that the crude incidence rate was higher in females. However, this ratio was different from the ratio of 2:1 in other Western countries. Huang et al had a culturally based explanation for this observation: in Taiwan, most postpartum females receive special nourishment and herbal medicine supplements daily for at least 1 month after each pregnancy. Therefore, our females have a higher risk of exposure to a potent carcinogen in some herbal medicine, aristolochic acid, which is well-known to cause UTUC. ${ }^{15}$

Patients who underwent diagnostic URS were at a higher risk of IVR after RNU when they had undergone URS before RNU but did not have a negative impact on CSS, OS, RFS, or MFS. ${ }^{14}$ In our study, preoperative ureter manipulation was an independent factor for bladder recurrence. Unlike previous studies, we included patients who underwent ureter stenting, and the result showed that it was independent for bladder recurrence but not related to OS. This implies the need for prophylactic intravesical chemotherapy after nephroureterectomy as diagnostic URS has an important role in the diagnosis and treatment of UTUC.

The prognostic role of operation method has been debated in the literature. Pooled data showed significantly increased risk of IVR in patients treated with laparoscopic RNU. ${ }^{4}$ In our study, most of the patients underwent laparoscopic RNU (48.8\%), and the surgical approach was not associated with bladder recurrence or OS in our study. 
The present study has several limitations. First, this is a retrospective study representing single-centre data. Second, patients who received non-surgical treatment were excluded from the analysis. Finally, lack of information on local recurrence and distant metastasis may reduce the strength of the findings. Therefore, further studies are necessary.

\section{Conclusions}

Bladder recurrence $(25.8 \%$ in 3 years) was common in UTUC after RNU, and early bladder recurrence (within 10 months) was associated with more relapsing high-risk NMIBC. Preoperative ureter manipulation was identified as an independent factor associated with early recurrence. These patients may need more intensive monitoring to undergo prophylactic intravesical chemotherapy after nephroureterectomy.

\section{Acknowledgments}

We thank the Chang Gung Memorial Hospital for the financial aid (CORPG3F0271, CORPG3F0281).

\section{Disclosure}

The authors report no conflicts of interest in this work.

\section{References}

1. Roupret M, Babjuk M, Comperat E, et al. European Association of urology guidelines on upper urinary tract urothelial carcinoma: 2017 update. Eur Urol. 2018;73(1):111-122. doi:10.1016/j.eururo.2017. 07.036

2. Soria F, Shariat SF, Lerner SP, et al. Epidemiology, diagnosis, preoperative evaluation and prognostic assessment of upper-tract urothelial carcinoma (UTUC). World $J$ Urol. 2017;35(3):379-387. doi:10.1007/s00345-016-1928-x

3. Li CC, Chang TH, Wu WJ, et al. Significant predictive factors for prognosis of primary upper urinary tract cancer after radical nephroureterectomy in Taiwanese patients. Eur Urol. 2008;54(5):1127-1134. doi:10.1016/j.eururo.2008.01.054

4. Seisen T, Granger B, Colin P, et al. A systematic review and meta-analysis of clinicopathologic factors linked to intravesical recurrence after radical nephroureterectomy to treat upper tract urothelial carcinoma. Eur Urol. 2015;67(6):1122-1133. doi:10.1016/j.eururo. 2014.11.035
5. Habuchi T, Yamada H, Kakehi Y, Yoshida O, Takahashi R, Suglyama T. Metachronous multifocal development of urothelial cancers by intraluminal seeding. Lancet. 1993;342(8879):1087-1088. doi:10.1016/ 0140-6736(93)92066-3

6. Jones TD, Wang M, Eble JN, et al. Molecular evidence supporting field effect in urothelial carcinogenesis. Clin Cancer Res. 2005;11 (18):6512. doi:10.1158/1078-0432.CCR-05-0891

7. O'Brien T, Ray E, Singh R, Coker B, Beard R. Prevention of bladder tumours after nephroureterectomy for primary upper urinary tract urothelial carcinoma: a prospective, multicentre, randomised clinical trial of a single postoperative intravesical dose of mitomycin C (the ODMIT-C Trial). Eur Urol. 2011;60(4):703-710. doi:10.1016/j.eururo.2011.05.064

8. Takaoka E, Hinotsu S, Joraku A, et al. Pattern of intravesical recurrence after surgical treatment for urothelial cancer of the upper urinary tract: a single institutional retrospective long-term follow-up study. Int J Urol. 2010;17(7):623-628. doi:10.1111/j.1442-2042.2010.02539.x

9. Kim KH, You D, Jeong IG, Hong JH, Ahn H, Kim CS. Muscleinvasive bladder cancer developing after nephroureterectomy for upper urinary tract urothelial carcinoma. Urol Oncol. 2013;31 (8):1643-1649. doi:10.1016/j.urolonc.2012.04.014

10. Xylinas E, Colin P, Audenet F, et al. Intravesical recurrence after radical nephroureterectomy for upper tract urothelial carcinomas: predictors and impact on subsequent oncological outcomes from a national multicenter study. World J Urol. 2013;31(1):61-68. doi:10.1007/s00345-012-0957-3

11. Kishimoto N, Takao T, Kuribayashi S, et al. The neutrophil-tolymphocyte ratio as a predictor of intravesical recurrence in patients with upper urinary tract urothelial carcinoma treated with radical nephroureterectomy. Int $J$ Clin Oncol. 2017;22(1):153-158. doi:10.1007/s10147-016-1040-7

12. Kim M, Moon KC, Choi WS, et al. Prognostic value of systemic inflammatory responses in patients with upper urinary tract urothelial carcinoma. World J Urol. 2015;33(10):1439-1457. doi:10.1007/ s00345-015-1484-9

13. Tanaka N, Kikuchi E, Kanao K, et al. Independent predictors for bladder outcomes after treatment of intravesical recurrence following radical nephroureterectomy in patients with primary upper tract urothelial carcinoma. Ann Surg Oncol. 2014;21(9):3151-3158. doi:10.1245/s10434-014-3657-y

14. Guo RQ, Hong P, Xiong GY, et al. Impact of ureteroscopy before radical nephroureterectomy for upper tract urothelial carcinomas on oncological outcomes: a meta-analysis. BJU Int. 2018;121 (2):184-193. doi:10.1111/bju.14053

15. Huang CC, Su YL, Luo HL, et al. Gender is a significant prognostic factor for upper tract urothelial carcinoma: a large hospital-based cancer registry study in an endemic area. Front Oncol. 2019;9:157. doi:10.3389/fonc. 2019.00157

16. Galon J, Costes A, Sanchez-Cabo F, et al. Type, density, and location of immune cells within human colorectal tumors predict clinical outcome. Science. 2006;313:1960-1964. doi:10.1126/science.1129139

17. Altman DG, Lausen B, Sauerbrei W, Schumacher M. Dangers of using "optimal" cutpoints in the evaluation of prognostic factors. J Natl Cancer Inst. 1994;86:829-835. doi:10.1093/jnci/86.11.829

\section{Publish your work in this journal}

Cancer Management and Research is an international, peer-reviewed open access journal focusing on cancer research and the optimal use of preventative and integrated treatment interventions to achieve improved outcomes, enhanced survival and quality of life for the cancer patient.
The manuscript management system is completely online and includes a very quick and fair peer-review system, which is all easy to use. Visit http://www.dovepress.com/testimonials.php to read real quotes from published authors. 